\title{
RESEARCH AND REPORTS
}

\section{Single Unit Transfusions in a Community Medical Center}

KAREN P. O'CONNOR, DEBRA SNOWBERGER

\begin{abstract}
Academic medical centers have implemented comprehensive patient blood management programs to reduce potential adverse transfusion effects. A retrospective study of single unit transfusions was conducted at a 319 bed community medical center to determine single unit transfusion practice patterns. Patient records of 535 single unit recipients were examined for gender, age and change in hemoglobin and hematocrit. Females (mean age 67) accounted for $64 \%$ of recipients, with a mean increase in hemoglobin of $1.3 \mathrm{~g} / \mathrm{dL}$. Males (mean age 67) had a mean increase of $0.9 \mathrm{~g} / \mathrm{dL}$. An incidental finding was that laboratory assessment of hemoglobin was unavailable for $6 \%$ (pre transfusion) and $15 \%$ (post transfusion) of recipients. The proportion of single units transfused on a monthly basis ranged from $0.02 \%$ to $0.05 \%$. No change toward increased use of single unit transfusion was identified. A formal patient blood management program is recommended as a next step in providing appropriate transfusion therapy.
\end{abstract}

INDEX TERMS: Transfusions, Erythrocytes, Transfusion Medicine, Hemoglobin, Anemia

Clin Lab Sci 2015;28(3):167

Karen P. O'Connor MS,MLS(ASCP)SBB, Washington College, Chestertown, $M D$

Debra Snowberger MT(ASCP), Anne Arundel Community College, Annapolis, $M D$

Address for Correspondence: Karen P. O'Connor, Toll S 125, Washington College, Chestertown, MD 21620

\section{INTRODUCTION}

The use of blood transfusion for therapeutic purposes was posited by the early Greeks and has become an accepted and successful therapy. The ability to use blood as a therapeutic modality was enhanced by the discovery of the $\mathrm{ABO}$ blood group system by Landsteiner in $1901,{ }^{1}$ the discovery of the Rh Blood group system by Landsteiner and Weiner in $1941,{ }^{2}$ and the development of blood collection, anticoagulation and storage throughout the $20^{\text {th }}$ century. ${ }^{3}$

The therapeutic benefit of transfusion derives from several characteristics of whole blood. Whole blood contains red blood cells, which carry oxygen required for optimal cellular and tissue function; platelets, an essential element for clot formation, and a variety of proteins required for successful clot formation. Modern blood donation and processing generally yields three components, each intended to address a specific deficit in the transfusion recipient. Red Blood Cells (RBC) are used to improve oxygen availability in individuals with a physiologic deficit due to anemia or acute blood loss. Platelet concentrates, usually obtained by apheresis from a single donor, correct a severe decrease in platelet count that may result in catastrophic bleeding or as replacement due to acute blood loss. Plasma separated from a whole blood donation is frozen to preserve clotting proteins. It is thawed prior to use to correct clotting factor deficiencies or maintain intravascular volume. $^{4}$

Transfusion benefits can be negated by undesirable outcomes that affect patient morbidity and mortality. Negative outcomes range in severity from minor allergic reactions to death. Less severe consequences are divided into several categories. These include transmission of blood- borne pathogens, circulatory overload and a range of immunologically-mediated effects. Infectious disease testing has decreased the transmission of many blood-borne diseases, yet the emergence of previously unrecognized blood-borne diseases present an ongoing transfusion hazard. ${ }^{5}$ Immunologically-mediated problems, including alloimmunization to blood group antigens, acute lung injury mediated by non-self proteins, and or allergic reactions to non-self proteins are traced to specific donor-recipient cellular 
interaction. Physiologic challenges mediated by transfusion include circulatory overload related to fluid imbalance. ${ }^{6,7}$ The most severe consequence results from transfusion of the incorrect $\mathrm{ABO}$ type, with catastrophic immune-mediated intravascular hemolysis and subsequent organ failure. The risk of immunologic response to non-self antigens, as well as transmission of unrecognized infectious agents increases with each unit of allogeneic RBCs administered. Recent commentary questions the use of blood transfusion as a first-line therapy because of the varied and sometimes profound negative effects on the patient. ${ }^{8,9}$

Transfusion practice was driven by studies published in the 1960s indicating that if blood transfusion was required, two units of blood were administered. ${ }^{10}$ The emergence of specific component transfusion did not alter the paradigm. Over the past 20 years and particularly in the past 5 years, it is recognized that blood transfusion therapy should be used after careful consideration of the benefits and risks. Quality standards developed by both the Food and Drug Administration and voluntary accreditation agencies such as the American Association of Blood Banks and The Joint Commission no longer focus on number of units as an indicator, but instead consider therapeutic impact on the patient. This has been augmented by the development and implementation of a multidisciplinary approach to treating a patient who may require blood transfusion. Patient blood management (PBM), as it is called, considers alternative approaches and provides guidance and support for appropriate use of blood and blood products. ${ }^{11-14}$ It has been demonstrated that this type of evaluation results in effective use of single unit transfusions, improving therapeutic outcome and reducing the risk of negative consequences. ${ }^{15-17}$ Academic medical centers have led this change in practice, implementing $\mathrm{PBM}$ as a result of a culture within an academic setting that is driven by inquiry and research to improve practices. Academic medical centers often have more resources and personnel to effect these changes. Practice patterns in a community setting are influenced by the paradigms followed at the time practitioners were trained and by the level of active engagement in transfusion medicine within the institution.

The purpose of this study was to examine the frequency of single unit $\mathrm{RBC}$ transfusions in a community hospital setting. A shift in single unit transfusion frequency may indicate a shift in the practice paradigm for RBC transfusion outside of academic medical centers. A retrospective review of single unit transfusion records was conducted at a 319 bed acute care medical center offering a full range of services for both inpatients and outpatients. The institution services a catchment area with a population of approximately 407,000. The Emergency Department is one of the busiest in the state of Maryland, with over 104,000 visits in calendar year 2012. The transfusion service provides 24 hour service and is the tissue bank for the medical center.

\section{MATERIALS AND METHODS}

A retrospective study of patient records was conducted with approval of the Office of Human Research Institutional Review Board of The George Washington University, approval of the Human Subjects Review Committee at the University of Maryland Baltimore Washington Medical Center and in accordance with the requirements of the Director of Health Information and Privacy Officer at UM Baltimore Washington Medical Center.

Blood Bank extraction reports (Sunquest Information System V 7.0 Build 7.0 1003) dated between February 2011 and June 2013 were reviewed to identify eligible patients. Patients were eligible if they received no more than a single unit of RBC in a rolling 12 month period. Recipients of autologous RBC were excluded. Additional information was derived from the Blood Bank Summary Report for calendar years 2011, 2012, and through June 2013. The institution introduced the EPIC electronic medical record system in August, 2012 (EPIC 2012 Portfolio IU3).

Data collected for the single unit recipients included sex, age, pre-transfusion hemoglobin and hematocrit and post-transfusion hemoglobin and hematocrit. Prior to implementation of the EPIC system, diagnosis was not readily available and was not collected.

Data analysis was performed using computer software (SPSS Statistics, Version 22, IBM Corporation and Excel, Microsoft Corporation). Descriptive statistics were applied to the patient data. The frequency of single unit transfusions on a monthly basis was analyzed using the Chi Square test to determine if there was a significant change in the proportion of single unit RBC 
transfusions over the time period studied.

\section{RESULTS}

The review resulted in a total of 535 individual records that met the criteria for the study. In each case both age and gender were recorded, as presented in Table 1 . The majority of single unit recipients were females. No difference in mean age was observed.

\begin{tabular}{ccccc}
\hline \multicolumn{5}{c}{ Table 1. Gender and age, single unit RBC transfusions } \\
\hline Gender & Number & Percent & $\begin{array}{c}\text { Mean } \\
\text { Age (yrs) }\end{array}$ & $\begin{array}{c}\text { Age } \\
\text { Range }\end{array}$ \\
\hline F & 344 & 64.4 & 67.56 & $19-99$ \\
M & 191 & 35.6 & 67.04 & $6-97$ \\
& 535 & 100 & & \\
\hline
\end{tabular}

The mean change in hemoglobin post-transfusion for both men and women is as expected, at an average of $1.1 \mathrm{~g} / \mathrm{dL}$ (Table 2). Measurement of pre- and posttransfusion hemoglobin and /or hematocrit is a generally accepted marker of the effectiveness of the therapy. Figure 1 illustrates the gaps in measuring the need for and effectiveness of RBC transfusion therapy.

\begin{tabular}{|c|c|c|}
\hline & $\mathrm{N}$ & Mean change $(\mathrm{g} / \mathrm{dL})$ \\
\hline $\mathrm{F}$ & $278^{*}$ & $1.3 \dagger$ \\
\hline M & $154^{*}$ & $0.9 \dagger$ \\
\hline
\end{tabular}

In order to determine the rate of single unit transfusions on a monthly basis, both annual and monthly statistics were reviewed. The medical center transfused 7014 allogeneic RBC units in calendar year 2011, 7229 RBC in 2012 and was projected to transfuse just over 8000 RBC in 2013, based on numbers for the first 6 months. Figure 2 illustrates the monthly rate of single RBCs transfused over the course of the study. No data were available for January 2012. Pearson Chi Square analysis showed no change in the proportion of single unit transfusion at $\mathrm{p}<0.01$.

\section{DISCUSSION}

The information gathered during the study provides a picture of the prevalence of single unit RBC transfusions in a community hospital setting, including associated laboratory measures of effect. Reviews of the epidemiology of RBC transfusion are available that examine larger populations and focus on specific diseases or surgical interventions. ${ }^{18-20}$ In contrast, this study crosses all categories of recipients of allogeneic transfusions.

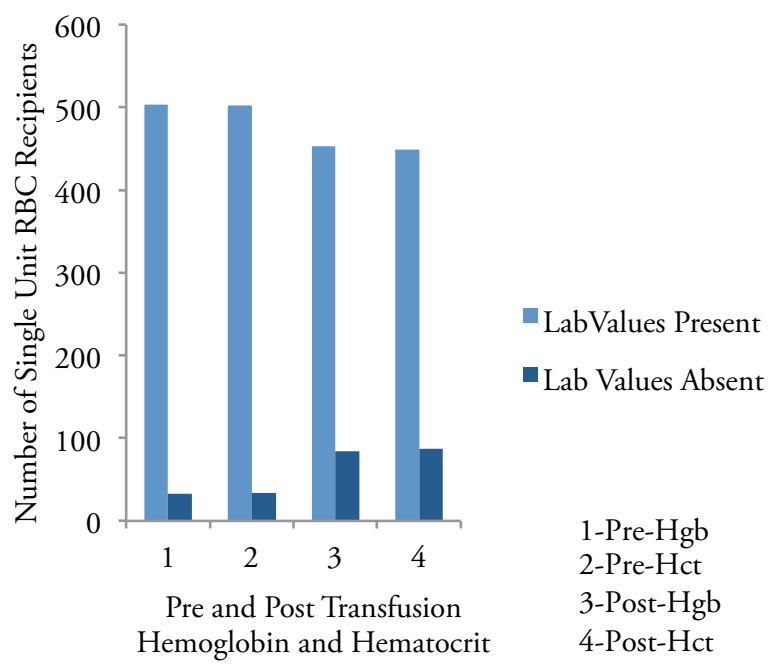

Figure 1. Availability of Laboratory Values Supporting Transfusion Need and Result

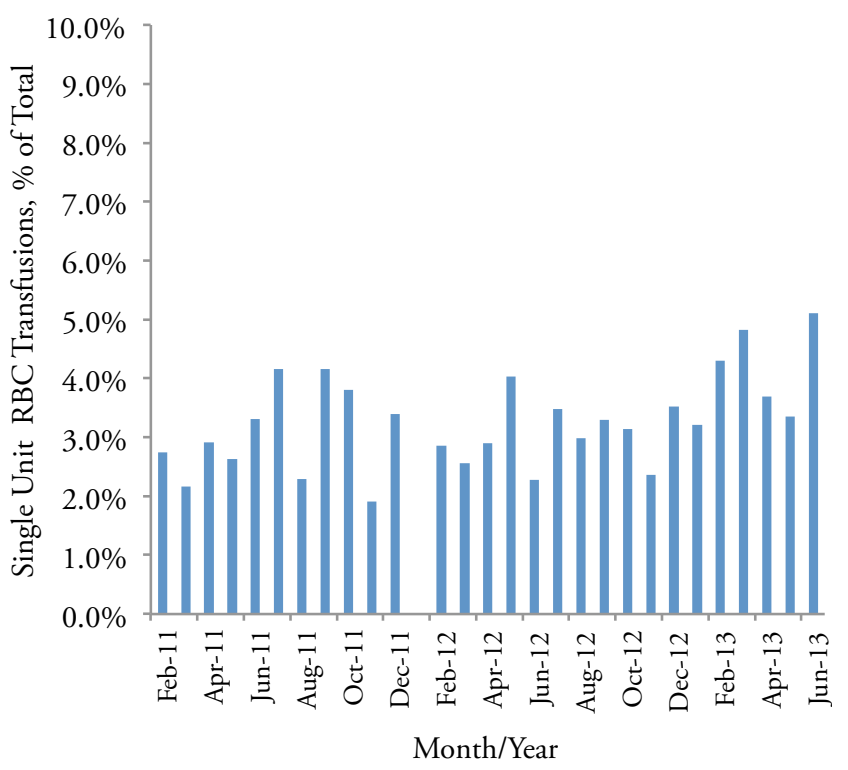

Figure 2. Percentage of single unit RBC transfusions per month . A retrospective analysis of monthly total transfusion data isolated single unit RBC transfusions versus 2 or more units. The null hypothesis is that there is no change in the proportion of single unit transfusions across the study period. Chi Square analysis yields a value of 32.15 and $\mathrm{p}=$ 0.227 . Thus the null is not rejected and the results show no significant difference in number of single unit RBC transfusions. 
The gender distribution for RBC transfusion has been reported by various investigators beginning in $1966 .{ }^{18-20}$ In the reports of Reece and Beckett, Vamvakas and Taswell, and Cobain et. al, more females than males were transfused by a margin of $3 \%$ to $20 \%$. Looking at single units per transfusion episode, Barr et. al. (2010) found that $58 \%$ of recipients were female and $42 \%$ were male. ${ }^{20}$ These reports are supported by our finding that $64 \%$ of single unit recipients were female.

The age distribution of single unit RBC recipients is almost identical, with a mean age for men of 67.04 years and women at 67.56 years. The finding is consistent with reports that from $53 \%$ to $71 \%$ of RBC recipients are over the age of 60 years. ${ }^{20,21}$

The need for transfusion is based on physiologic signs and symptoms of anemia as well as laboratory values of hemoglobin and hematocrit. Guidelines are provided for physicians indicating what value hemoglobin and/or hematocrit constitutes a valid transfusion trigger. These guidelines are part of a mandated quality assurance system for both the medical staff and the blood bank. ${ }^{22}$ At the study institution, the trigger value is a hemoglobin less than or equal to 8.0 grams/dL in the absence of acute bleeding or evidence of cardiac distress. The implementation of computerized physician order entry in August 2012 reinforced the use of the trigger value when ordering blood, with prompts to document the clinical situation if the value was to be overridden. In addition, a modified prospective review by the blood bank is part of the standard operating procedure to document exceptions. In spite of these process safeguards, $6 \%$ of single unit RBC recipients did not have a pretransfusion value available in the blood bank records, as presented in Figure 1. In some instances, this is attributed to outpatient transfusions wherein the lab values were obtained at an outside laboratory. In others, an acute bleed that was immediately corrected could have resulted in transfusion of a single unit in the absence of a pretransfusion laboratory value.

Assessing the effectiveness of a transfusion is achieved by documenting clinical improvement and evaluation of laboratory values of hemoglobin ( $\mathrm{Hgb})$ and/or hematocrit $(\mathrm{Hct})$. The laboratory values are obtained within 8 to 12 hour after the transfusion. The expected increment of $1 \mathrm{gm} / \mathrm{dL}(\mathrm{Hgb})$ or $3 \%(\mathrm{Hct})$ provides an indication of effectiveness and must be documented to meet quality and reimbursement requirements. In our study, a surprising $16 \%$ of recipients had neither value recorded after transfusion (Figure 1). The reasons for missing values can be divided into those dependent on patient condition and those that resulted from operational problems. In the former category reasons include physical transfer or discharge from the facility prior to obtaining a sample, patient refusal to have blood drawn or patient death. Operational factors include unacceptable sample for testing that is not subsequently redrawn (hemolysis, clotting, labeling) or failure to order the post-transfusion test (nurse error or physician order not given). Additional investigation of this finding would be beneficial in improving documentation of effectiveness.

The purpose of the study was to determine the prevalence of single unit transfusions in a community hospital, in consideration of a shift in the view of this approach to transfusion therapy in the academic transfusion medicine community. Academic medical centers developed this change in practice, increasing the proportion of single unit RBC transfusions as a result of the implementation of patient blood management. Academic medical centers often have more resources and personnel to effect these changes. In addition, there is the expectation of research into process and process improvement that is not always present in the community hospital setting. Practice patterns in a community setting are influenced by the paradigms followed at the time practitioners were trained, with older staff members used to the" two or none" approach to transfusion. Transfusion practices are further influenced by the absence of Blood Bank Directors with a strong background in transfusion medicine within community medical centers.

There was no formal patient blood management (PBM) program at the institution at the time the study was conducted. The process in place relied on the patient blood utilization and management team, led by the blood bank manager and the blood bank director. All transfusion data was reviewed on a monthly basis to assure quality and compliance with Medicare Conditions of Participation, The Joint Commission accreditation, AABB accreditation and CAP accreditation. Undocumented exceptions were identified and individual physicians were contacted directly to enforce accepted practice within the 
institution. This approach, however, does not meet the criteria of a formal patient blood management program. ${ }^{23,24}$ In the absence of such a program, there was no change in the proportion of single unit transfusions compared to the transfusion of two or more units during the time period studied.

Patient blood management is focused on using all members of the healthcare team to assess hemodynamic status and determine which intervention to correct a deficiency is most appropriate for the patient. ${ }^{13}$ This may include reducing surgical or other iatrogenic blood loss, use of medications to stimulate hematopoesis or adherence to strict guidelines for blood use. ${ }^{11}$ The goal is to achieve correction of anemia without allogeneic $\mathrm{RBC}$ transfusion thus reducing the risks associated with it. An associated benefit is reduced cost by conservative use of a limited resource. Kumar et. al. at the Cleveland Clinic demonstrated that implementation of a multidisciplinary approach to changing transfusion practice reduced overall transfusion rates over a three year period. ${ }^{12}$ In a review of similar literature, Tinmouth et. al. (2005) reported a reduction of $12-65 \%$ in the number of units transfused once a more focused program was implemented. In order to drive this type of change in practice patterns, a combination of measures that included written guidelines, prospective review, personal feedback and medical staff educational programs achieved success. Examining transfusion statistics by service line and even individual physician provided the basis for both education and practice modification. ${ }^{12}$ The implementation of computerized physician order entry (CPOE) gives the transfusion service a tool with which to improve utilization rates because of the ease of data capture for auditing. ${ }^{26-28}$

$\mathrm{Ma}$ et.al. reported that the number of $\mathrm{RBC}$ units given can be reduced simply by making a clinical and laboratory evaluation of the impact of each unit of blood given before automatically transfusing a second or third unit. ${ }^{15}$ This approach has resulted in a significant reduction in blood utilization at the University of Alabama Birmingham. ${ }^{26}$ Consensus was developed to reduce the hemoglobin threshold for transfusion to 7.0 $\mathrm{g} / \mathrm{dL}$. The CPOE system was structured to require justification for orders of more than one unit of RBC in the absence of active bleeding. Relying on CPOE screen prompts alone will not automatically result in appropriate blood usage. ${ }^{29}$ A PBM program should include a variety of means to educate both physician and nursing staff, provide feedback in a timely and nonthreatening manner, ongoing educational programs and meaningful accountability. ${ }^{30}$

Creating an environment for practice change is one factor in successful implementation of PBM programs. The influence of peers is significant. ${ }^{31}$ Support of both the medical center administration and the leading physician RBC users is also very important at the outset of the process. With engaged leadership, the development of consensus is more likely, which will enhance the success of making a change.

The study presented here is limited in that it is retrospective. Additional information about diagnosis and clinical outcome would be valuable in making the results generalizeable to community medical centers of comparable size. A growing body of literature provides substantial information on transfusion best practices, how to work with members of the healthcare team to effect change, and how to measure patient benefit. Based on the data presented here, the implementation of a formal patient blood management program is a logical next step.

\section{ACKNOWLEDGEMENTS}

The author would like to acknowledge the following individuals for their help and guidance in the preparation of this study: Alan Morrison, MD, Marcia Firmani, PhD, and Karen Schlumpf, PhD.

\section{REFERENCES}

1. Landsteiner $\mathrm{K}$. Uber agglutinationserscheinungen normalen menschlichen blutes.Klin Wsch 1901;14:1132.

2. Landsteiner $\mathrm{K}$ and Weiner AS. Studies on an agglutinogen (Rh) in human blood reacting with anti-Rhesus sera and with human isoantibodies. J Exp Med 1941;74:309.

3. Giangrande PLF. The history of blood transfusion. Brit J of Haematol 2000;110:758-67.

4. Aubuchon JP. Hemotherapy decisions and their outcomes. Chapter 20, Technical Manual $16^{\text {th }}$ Edition, 2008, AABB.

5. Stramer SL, Hollinger FB, Katz LM, Kleinman S, Metzl PS, Gregory KR, et al. Emerging infectious disease agents and their potential threat to transfusion safety. Transfusion 2009; 49(s2):1s-29s.

6. Popovsky MA. Transfusion and the lung: circulatory overload and acute lung injury. Vox Sang 2004;87s2:62-5.

7. Gilliss BM, Looney MR, Gropper MA. Reducing noninfectious risks of transfusion. Anesthesiology 2011;115:63542.

8. Vamvakas EC. Establishing causation in transfusion medicine and related tribulations. Trans Med Rev 2011;25:81-8. 
9. Isbister JP, Shander A, Spahn DR, Erhard J, Farmer SL, Hofmann A. Adverse blood transfusion outcomes: establishing causation. Trans Med Rev 2011;25:89-101.

10. Crosby WH. The single unit transfusion. Transfusion 1964;4:329-30.

11. Shander A, Javidroozi M, Perelman S, Puzio T, Lobel G. From bloodless surgery to patient blood management. Mt Sinai J Med 2012;79:56-65.

12. Kumar A, Figueroa PI, Gowans KL, Parker BM, Proctor AW, Benitez-Santana SM, et al. An evolution in blood management: past, present and future. Q Manage Health Care 2011;20:31121.

13. Becker J, Shaz B. Guidelines for patient blood management and blood utilization. AABB 2011;Bethesda, MD.

14. Gammon HM, Waters JH, Watt A, Loeb JM, Donini-Lenhoff A. Developing performance measures for patient blood management. Transfusion 2011;51:2500-9.

15. Ma M, Eckert K, Railey F, Chin-Yee I. A retrospective study evaluating single-unit red blood cell transfusion in reducing allogeneic blood exposure. Transfusion Med 2005;15:307-12.

16. Berger MD, Gerber B, Am K, Senn O, Schanz U, Stussi G. Significant reduction of red blood cell transfusion requirements by changing form a double-unit to a single-unit transfusion policy in patients receiving intensive chemotherapy or stem cell transplantation. Haematologica 2012;97:116-22.

17. Gombotz H. Patient blood management: a patient-orientated approach to blood replacement with the goal of reducing anemia, blood loss and the need for blood transfusion in elective surgery. Transfus Med Hemoth 2012;39:67-72.

18. Reece RI, Beckett RS, Epidemiology of single unit transfusion. JAMA 1966;195:113-8.

19. Vamvakis EC, Taswell HF. Epidemiology of blood transfusion. Transfusion 1994;34:464-70.

20. Barr PJ, Donnelly M, Morris K, Parker M, Cardwell C, Bailie KEM. The epidemiology of red cell transfusion. Vox Sang 2010;99:239-50.

21. Cobain TJ, Vamvakas EC, Wells A, Titlestad K. A survey of the demographics of blood use. Transfusion Med 2007;17:1-
15.

22. Carson JL, Hill S, Carless P, Hebert P, Henry D. Transfusion triggers: a systematic review of the literature. Trans Med Rev 2002;16:187-1999.Levinson, DR. Medicare's response to alleged serious events. Department of Health and Human Services 2011; OEI-01-08-00590.

23. Hannon T, and Gross I. Transfusion guidelines: development and impact on patient blood management. In The Transfusion Committee, Putting Patient Safety First, 2nd Ed, 2013, AABB Press, Bethesda, MD.

24. Sazama K, The evolving role of accrediting organizations. The Transfusion Committee, Putting Patient Safety First, $2^{\text {nd }}$ Edition, 2013, AABB, Bethesda, MD.

25. Tinmouth A, MacDougall L, Ferguson D. Amin M, Graham ID, Hever PC, Wilson K. Reducing the amount of blood transfused: A systematic review of behavioral interventions to change physicians' transfusion practices. Arch Int Med 2005;165:845-52.

26. Kim JY, Dzik WH, Dighe AS, Lewandrowski KB. Utilization management in a large urban medical center: a 10 year experience. Am J Clin Path 2011;135:108-18.

27. Marques MB, Polhill SB, Waldrum MR, Johnson JE, Timpa J, Patterson A, Salzman D. How we closed the gap between red blood cell utilization and whole blood collections in our institution. Transfusion 2012;52:1857-67.

28. Haspel RL, Uhl L. How do I audit hospital blood product utilization? Transfusion 2012;52:227-30.

29. Scheurer DB, Roy CL, McGurk S, Kachalia A. Effectiveness of computerized physician order entry with decision support to reduce inappropriate blood transfusions. JCOM 2010;17:1726.

30. Salem-Schatz SR, Avorn J, Soumerai SB. Influence of clinical knowledge, organizational context and practice style on transfusion decision making; implications for practice change strategies. JAMA 1990;264:471-5.

31. Rehm JP, Otto PS, West WW, Grange JJ, Halloran BG, Lynch TG, Baxter BT. Hospital-wide educational program decreases red blood cell transfusions. J Surg Res 1998;75:183-6 